\title{
Echocardiography evaluation of bronchopulmonary dysplasia-associated pulmonary hypertension: a retrospective observational cohort study
}

\author{
Yang Du ${ }^{1 \#}$, Lin Yuan ${ }^{1 \#}$, Jian-Guo Zhou ${ }^{1}$, Xiang-Yuan Huang ${ }^{2}$, Sam Bill Lin ${ }^{1}$, Meng Yuan ${ }^{1}$, Yue He ${ }^{1}$, \\ Wei-Ying Mao ${ }^{1}$, Dan-Yang $\mathrm{Ai}^{1}$, Chao Chen ${ }^{1}$ \\ ${ }^{1}$ Department of Neonatology, Children's Hospital of Fudan University, Shanghai, China; ${ }^{2}$ Department of Clinical Epidemiology, Children's Hospital \\ of Fudan University, Shanghai, China \\ Contributions: (I) Conception and design: Y Du, L Yuan, C Chen; (II) Administrative support: C Chen; (III) Provision of study materials or patients: \\ C Chen, JG Zhou; (IV) Collection and assembly of data: SB Lin, M Yuan, Y He, WY Mao, DY Ai; (V) Data analysis and interpretation: Y Du, \\ L Yuan, XY Huang; (VI) Manuscript writing: All authors; (VII) Final approval of manuscript: All authors. \\ \#These authors contributed equally to this work. \\ Correspondence to: Chao Chen, MD, PhD. Department of Neonatology, Children's Hospital of Fudan University, 399 Wanyuan Road, Minhang \\ District, Shanghai 201102, China. Email: chen6010@163.com.
}

Background: Echocardiography has poor accuracy in grading the severity of pulmonary hypertension (PH) compared to cardiac catheterization. However, the relationship between degree of $\mathrm{PH}$ and prognostic outcomes remains uncertain. Our primary objective was to determine whether echocardiogram-assessed $\mathrm{PH}$ severity is associated with mortality and hospital readmission in the first year of life.

Methods: A retrospective cohort study of infants born less than 32 weeks of gestational age with bronchopulmonary dysplasia (BPD) underwent echocardiography was performed. Echocardiograms were performed at 36-38 weeks postmenstrual age. Data during hospitalization and post-discharge collected at 1-year age were analyzed with cox regression models and logistic regression models to identify the association of PH severity with mortality and readmission. Area under curve (AUC) was calculated to examine the accuracy of these models to reflect the likelihood of outcomes.

Results: Fifty-six of 237 (23.6\%) infants were diagnosed as PH. Moderate and severe PH was significantly associated with mortality during the first one year of life (moderate PH vs. none HR =26.58, 95\% CI: 4.40160.78, $\mathrm{P}<0.001$; severe $\mathrm{PH}$ vs. none $\mathrm{HR}=36.49$, 95\% CI: 5.65-235.84, $\mathrm{P}<0.001$ ). Male, preeclampsia and inhaled nitric oxide were also associated with mortality. Mild $\mathrm{PH}$ was significantly associated with readmission (OR =2.42, 95\% CI: 1.12-5.26, P=0.025), but not associated with mortality (HR =2.09, 95\% CI: 0.43-10.18, $\mathrm{P}=0.36$ ). The $\mathrm{PH}$ severity model based on echocardiography accurately informed mortality (AUC 0.79 ).

Conclusions: Echocardiogram-assessed PH severity is associated with prognostic outcomes, including mortality and readmission in very preterm infants with BPD. The severity of $\mathrm{PH}$ based on echocardiography is a potential predictor of mortality in the first year of life.

Keywords: Bronchopulmonary dysplasia (BPD); pulmonary hypertension (PH); echocardiography; prognosis

Submitted Jul 12, 2020. Accepted for publication Nov 26, 2020.

doi: $10.21037 / \mathrm{tp}-20-192$

View this article at: http://dx.doi.org/10.21037/tp-20-192

^ ORCID: 0000-0001-7630-819X. 


\section{Introduction}

Bronchopulmonary dysplasia (BPD), a severe chronic lung disease, which follows premature birth, is one of the most common complications in Neonatal Intensive Care Unit (NICU) $(1,2)$. According to current definition based on use of supplemental oxygen for at least 28 days, approximately $45 \%$ of extremely preterm infants develop BPD in China (3). It is one of the major drivers of mortality, prolonged hospitalization, and healthcare utilization after discharge $(4,5)$. Pulmonary arterial hypertension $(\mathrm{PH})$ is one of the most serious complications of BPD. Its pathogenesis is still poorly understood and is partly believed to be caused by secondary abnormal growth of pulmonary vessels (6-8). It is reported that $10-36 \%$ of babies with BPD develop PH. PH is closely associated with poor prognosis $(6,7,9-14)$.

Although the cardiac catheterization is the gold standard procedure for diagnosis of $\mathrm{PH}(15,16)$, the Pediatric Pulmonary Hypertension Network (17) and the American Heart Association (18) have recommended echocardiography, a less invasive tool, to screen for the presence of $\mathrm{PH}$ in infants with BPD. Mourani et al. (15) found that echocardiography performed well in screening for PH in infants with BPD, but it had limited performance in PH severity assessment. The study reported recently by Nawaytou (16), who also found similar findings that echocardiography had poor accuracy in grading the severity of PH evaluated by cardiac catheterization. Nevertheless, the relationship between degree of $\mathrm{PH}$ and prognostic outcomes, which may help classify illness severity, is poorly understood for lack of evidence.

In this study, our overall goal was to describe the shortterm outcomes of infants with BPD-associated PH in a retrospective cohort. Our primary objective was to determine whether echocardiogram-assessed $\mathrm{PH}$ severity is associated with mortality and hospital readmission during the first year of life.

We present the following article in accordance with the STROBE reporting checklist (available at http://dx.doi. org/10.21037/tp-20-192).

\section{Methods}

This is a retrospective observational cohort study that included infants, who were admitted to the NICU in Children's Hospital of Fudan University (CHFU), between July 2014 and June 2018. The study was conducted in accordance with the Declaration of Helsinki (as revised in 2013). This study was approved by the Children's Hospital of Fudan University Institutional Review Board (IRB No. 2018-301), with a waiver of informed consent for retrospectively use of routine clinical data. Criteria for enrollment included premature infants, born less than 32 weeks of gestation age and had BPD, admitted to a CHFU NICU. Exclusion criteria included clinical evidence of severe congenital heart disease, which didn't include patent ductus arteriosus (PDA), patent foramen ovale (PFO) or atrial septal defect (ASD) $<1 \mathrm{~cm}$, and ventricular septal defect $<2 \mathrm{~mm}$; major congenital abnormality; chromosomal abnormality; Infants who died prior to 36 weeks postmenstrual age (PMA) or didn't perform echocardiogram from 36 weeks PMA to 38 weeks PMA were excluded from analysis.

BPD status and severity were respectively assessed at 28 days postnatal and 36 weeks PMA using a modification of the National Institutes of Health workshop definition (19). $\mathrm{BPD}$ is defined as requiring oxygen support for at least 28 days. At 36 weeks of PMA, infants with BPD without oxygen demand were considered to have mild BPD. In addition, infants with aerobic requirements $<30 \%$ were considered to have moderate BPD and those with a need for positive pressure ventilation/continuous positive pressure (PPV/CPAP) and/or oxygen requirement $\geq 30 \%$ to have severe BPD. Infants were considered small for gestational age (SGA), if the birth weight was below the 10th percentile for corresponding sex and gestational age (20). Infants were considered as extrauterine growth restriction (EUGR), if the growth values were below the 10th percentile for expectation based on estimated postmenstrual age at hospital discharge $(20,21)$.

We preformed echocardiogram of the preterm infants with BPD at 36-38 weeks PMA in the NICU to screen for PH. Echocardiographic measurements included tricuspid regurgitation velocity (TRJV), cardiac cavity, detectable shunt lesions (atrial septal defect, ventricular septal defect, patent ductus arteriosus, patent foramina ovale) and shunt direction $(7,17,22,23)$. The estimated systolic pulmonary artery pressure (sPAP) was calculated using a modified Bernoulli equation (TRJV^2*4) $(24,25)$. All measurements were performed according to the Pediatric Academy of Chinese Medical Association Newborn Pulmonary Hypertension consensus (26) on quantitative assessment in infants. The echocardiography was performed according to the same standard by one cardiologist blinded to clinical information and checked by another senior cardiologist who was also blinded to clinical information. $\mathrm{PH}$ was diagnosed 
by the senior cardiologist and classified as "none", "mild $\mathrm{PH}$ ", "moderate $\mathrm{PH}$ " and "severe $\mathrm{PH}$ ". Severity-graded criteria were provided in Table $\mathrm{S} 1$ in the online supplement. Routine information like maternal and perinatal characteristics, neonatal demographics, morbidities and treatment during hospitalization were retrieved from hospital information system.

The primary outcome was mortality after 36 weeks PMA during the first year after birth. An infant who was diagnosed as BPD at 36 weeks PMA and died after 36 weeks PMA and prior to the first one-year age was counted as mortality. For infants who survive CHFU discharge, the secondary outcome is readmission. This refers to one or more hospitalizations during the first year of life for infection, respiratory or cardiovascular causes.

Follow-up questionnaires were administered to parents either in-person or via telephone during the first one year of life, which included items regarding mortality, readmission and corresponding time.

\section{Statistical analyses}

All data were retrospectively collected and managed using the electronic database previously designed by researchers. Kruskal-Wallis analysis was used to compare categorical and continuous variables across survival outcomes and readmission status. Survival analysis was performed with cox regression model and Kaplan-Meier curves were plotted. A multivariable cox regression model was performed to identify the association between survival outcomes and the severity of $\mathrm{PH}$. Complete covariate information was required to estimate associations in the final analytic model selected. Potential confounders were identified on the basis of the results of Kruskal-Wallis analysis and clinical importance and were restricted to an appropriate number less than 12 , based on the number of events. A similar multivariable logistic regression model was performed to identify the association between readmission status and the severity of PH after excluding all dead cases. Covariates were selected with the method similar to the cox analytic model.

For comparison, separate models were created from $\mathrm{PH}$ severity alone, $\mathrm{PH}$ severity plus other covariates, and other covariates alone. Area under curve (AUC) was determined and compared among these models to examine the accuracy of these models to reflect the likelihood of survival outcomes. Descriptive statistics for patient characteristics are reported as count (percent) or median (interquartile range). In cox regression analysis, hazard ratios with two-sided
$95 \%$ confidence interval (CI) was provided. Also, odds ratios with two-sided $95 \%$ CI was provided in logistic regression analysis. $\mathrm{P}$ values of less than 0.05 were considered to indicate statistical significance. Statistical analysis was performed using $\mathrm{R}$ version 3.5.1 (R Project for Statistical Computing) and Stata 14 (Stata, College Station, TX, USA).

\section{Results}

During July 2014 to June 2018, 290 very preterm infants admitted to the NICU in Children's Hospital of Fudan University were diagnosed as BPD (Figure 1). Twenty-two infants with severe congenital heart disease and 5 with major congenital abnormality or chromosomal abnormality were excluded. Among these included patients, 237 (90.1\%) underwent echocardiogram assessment at 36-38 weeks PMA and were followed up at 1-year age after birth. Twenty-six very preterm infants, without echocardiogram assessment or follow-up data, were also excluded from analysis. Echocardiographic characteristics, in infants with $\mathrm{PH}$, were present in Table S2 in the online supplement. The TRJV was detectable in only 38 of the 56 infants. Characteristics of all the 237 infants included were presented in Table 1 . The median gestational age was 28 weeks, and the median birth weight was 1,080 grams. Eleven infants with $\mathrm{PH}(19.6 \%)$ died in the first year of life, and 5 within 100 days after birth. In nine of the cases, $\mathrm{PH}$ was considered a significant cause of death, often co-occurring with respiratory failure; the other 2 infants with mild $\mathrm{PH}$ died from respiratory failure. The differences in characteristics between survivors and non-survivors were also shown in Table 1. No significant differences were found between survivors and nonsurvivors in terms of gestational age, birth weight and SGA, preeclampsia, gestational diabetes, antenatal corticosteroids, mechanical ventilation (MV) at 7 days postnatal, PDA, grade 3 or 4 intraventricular hemorrhage (IVH), necrotizing enterocolitis (NEC) (Table 1). Noticeably, the PH severity was higher in non-survivors than in survivors. Kaplan-Meier survival plot shown in Figure 2 also demonstrated significantly less survival for subjects with higher $\mathrm{PH}$ severity. Moreover, survivors had shorter time on MV (8 vs. 29 days, $\mathrm{P}<0.001$; Table 1), lower severe $\mathrm{BPD}$ rate $(36.2 \%$ vs. $93.8 \%, \mathrm{P}<0.001$; Table 1$)$, higher non- $\mathrm{PH}$ rate $(79.6 \%$ vs. $31.3 \%, \mathrm{P}<0.001$; Table 1$)$, less iNO administration $(2.7 \%$ vs. $18.8 \%, \mathrm{P}<0.001$; Table 1$)$ and less sildenafil administration ( $2.7 \%$ vs. $18.8 \%, \mathrm{P}<0.001$; Table 1$)$, 


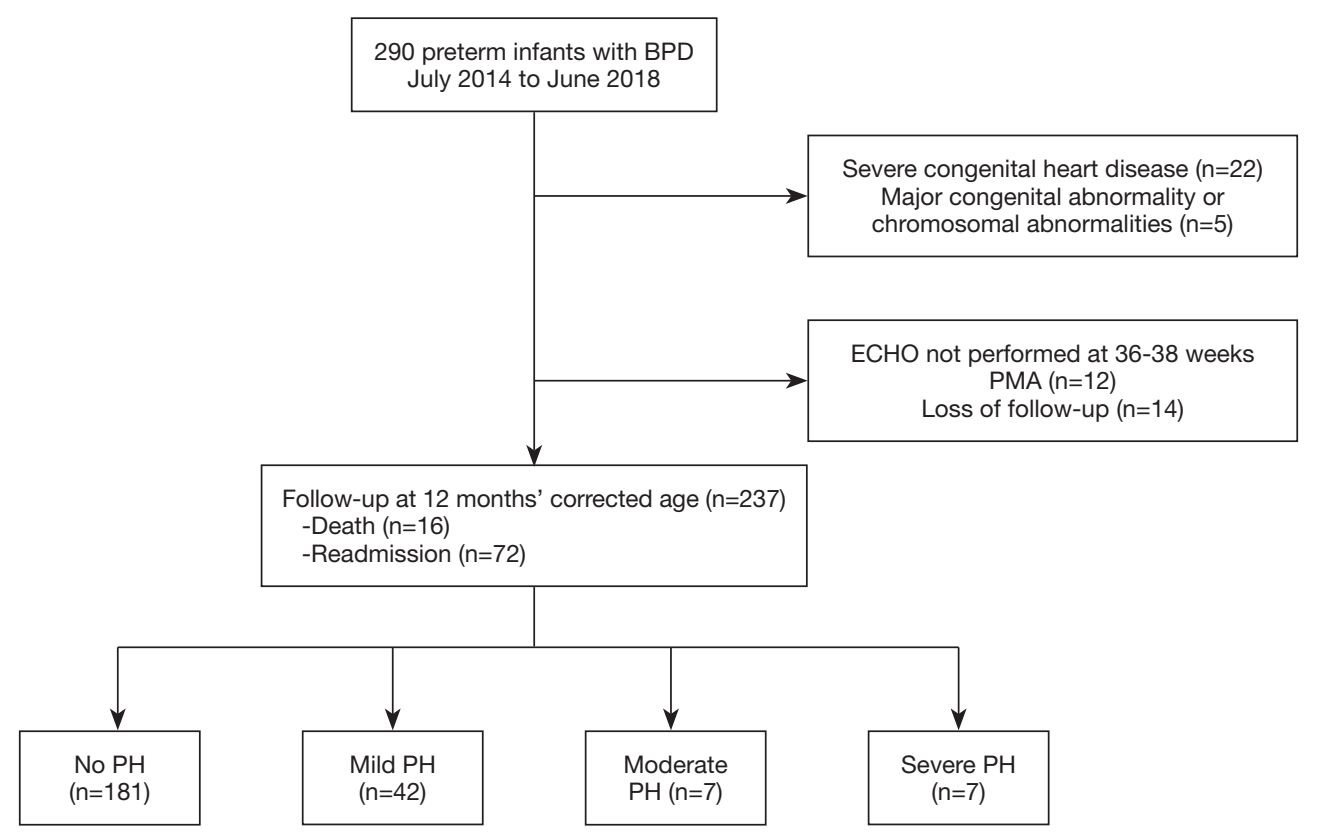

Figure 1 Flow chart of the study population. BPD, bronchopulmonary dysplasia; PH, pulmonary hypertension; ECHO, echocardiogram; PMA, post-menstrual age.

comparing with non-survivors.

Of 221 survivors, 72 (32.6\%) had readmission for infection, respiratory or cardiovascular reasons during the first one year of life. The comparison between infants with readmission and without readmission in terms of characteristics were shown in Table S3 in the online data supplement. The duration of $M V$ was longer for readmission infants (13 vs. 7 days, $\mathrm{P}<0.001$; Table S3), and the incidence of severe BPD was higher $(47.2 \% v s$. $30.9 \%, \mathrm{P}=0.008$; Table S3). Meanwhile, the incidence of non-PH was low (68.1\% vs. $85.2 \%, \mathrm{P}=0.002$. Table S3). Nevertheless, CMV infection rates were higher $(12.5 \%$ vs. 3.5\%, $\mathrm{P}=0.009$; Table $\mathrm{S} 3$ ) and more blood transfusions (93.1\% vs. $82.6 \%, \mathrm{P}=0.036$; Table $\mathrm{S} 3$ ). Sildenafil was administered more frequently $(5.6 \%$ vs. $0.7 \%, \mathrm{P}=0.022$; Table S3), and longer ICU stay (100 vs. 83 days, $\mathrm{P}<0.001$; Table S3).

In Figure 3 and Table S4 listed the parameters estimated in the multivariate Cox regression model. The model was estimated in the first year of life using prenatal and postnatal data (including echocardiographic-assessed $\mathrm{PH}$ severity of PMA at 36-38 weeks) and in the first year of life. The cox regression model covariate selected included: PH severity, gender, IVF-ET, preeclampsia, SGA, NEC,
EUGR, surfactant administration, diuretic administration, iNO and sildenafil administration. Moderate and severe $\mathrm{PH}$ had the largest estimated association with mortality during the first one year of life (moderate $\mathrm{PH} v s$. none $\mathrm{HR}=26.58$, 95\% CI: 4.40-160.78, $\mathrm{P}<0.001$; severe $\mathrm{PH}$ vs. none $\mathrm{HR}$ =36.49, 95\% CI: 5.65-235.84, $\mathrm{P}<0.001)$. However, mild PH was not significantly associated with survival outcomes (HR $=2.09$, 95\% CI: 0.43-10.18, P=0.36). Male, preeclampsia and iNO were also significantly associated with survival outcomes. The receiver operator curves for models using $\mathrm{PH}$ severity alone. PH severity plus other co-variables, and only other co-variables with respect to the likelihood of death are shown together in Figure 4. The AUC of the PH severity model is 0.79 , which can reach 0.85 when other covariates are combined. The parameter estimates from the multivariable logistic regression model selected to inform readmission during the first one year of life were presented in Figure S1 and Table S5 in the online supplement. Mild $\mathrm{PH}$ was significantly associated with readmission (OR $=2.42$, 95\% CI: $1.12-5.26, \mathrm{P}=0.025)$. The receiver operator curves for models using $\mathrm{PH}$ severity alone, $\mathrm{PH}$ severity plus other covariates, and only other covariates for likelihood of readmission were presented together in Figure S2. AUC of the PH severity model was 0.58 , and addition of other 
Table 1 Characteristics for all subjects, survivors and non-survivors

\begin{tabular}{|c|c|c|c|c|}
\hline Characteristics & All subjects & Survivors & Non-survivors & $P$ value \\
\hline Gestational age, week & 28 [27-29] & 28 [27-29] & 28 [27-29] & 0.72 \\
\hline Birth weight, gram & $1,080[930-1,250]$ & $1,080[930-1,250]$ & $1,045[805-1,270]$ & 0.42 \\
\hline SGA & $20(8.4 \%)$ & $18(8.1 \%)$ & $2(12.5 \%)$ & 0.55 \\
\hline \multicolumn{5}{|l|}{ Maternal complications } \\
\hline Multiple gestation & $86(36.3 \%)$ & $80(36.2 \%)$ & $6(37.5 \%)$ & 0.92 \\
\hline IVF-ET & $68(28.6 \%)$ & $61(27.6 \%)$ & $7(43.8 \%)$ & 0.17 \\
\hline Preeclampsia & $36(15.2 \%)$ & $31(14.0 \%)$ & $5(31.3 \%)$ & 0.06 \\
\hline Intrauterine distress & $25(10.6 \%)$ & $24(10.9 \%)$ & $1(6.3 \%)$ & 0.56 \\
\hline Antenatal corticosteroids & $113(47.7 \%)$ & $105(47.5 \%)$ & $8(50 \%)$ & 0.85 \\
\hline Cesarean section & $96(40.7 \%)$ & $90(40.9 \%)$ & $6(37.5 \%)$ & 0.79 \\
\hline \multicolumn{5}{|l|}{ Postnatal hospitalization } \\
\hline Surfactant & $190(80.2 \%)$ & $175(79.2 \%)$ & $15(93.8 \%)$ & 0.16 \\
\hline Mechanical ventilation support at 7 days & $155(65.4 \%)$ & $144(65.2 \%)$ & $11(68.8 \%)$ & 0.77 \\
\hline Days on MV & 9 [4-21] & 8 [3-19] & 29 [14-63] & $<0.001$ \\
\hline PDA & $197(87.6 \%)$ & $186(88.6 \%)$ & $11(73.3 \%)$ & 0.09 \\
\hline Moderate & $56(23.6 \%)$ & $55(24.9 \%)$ & $1(6.3 \%)$ & \\
\hline Severe & $95(40.1 \%)$ & $80(36.2 \%)$ & $15(93.8 \%)$ & \\
\hline PH severity & & & & $<0.001$ \\
\hline None & $181(76.4 \%)$ & $176(79.6 \%)$ & $5(31.3 \%)$ & \\
\hline Mild & $42(17.7 \%)$ & $39(17.7 \%)$ & $3(18.8 \%)$ & \\
\hline Moderate & $7(3.0 \%)$ & $4(1.8 \%)$ & $3(18.8 \%)$ & \\
\hline Severe & $7(3.0 \%)$ & $2(0.9 \%)$ & $5(31.3 \%)$ & \\
\hline CMV infection & $15(6.3 \%)$ & $14(6.3 \%)$ & $1(6.3 \%)$ & 0.99 \\
\hline Sepsis & $121(51.1 \%)$ & $112(50.7 \%)$ & $9(56.3 \%)$ & 0.67 \\
\hline EUGR & 175 (73.8\%) & $163(73.8 \%)$ & $12(75 \%)$ & 0.91 \\
\hline Blood transfusion & 205 (86.5\%) & $190(86.0 \%)$ & 15 (93.8\%) & 0.38 \\
\hline
\end{tabular}

Table 1 (continued) 
Table 1 (continued)

\begin{tabular}{|c|c|c|c|c|}
\hline Characteristics & All subjects & Survivors & Non-survivors & $P$ value \\
\hline Diuretic & 122 (51.5\%) & 111 (50.2\%) & $11(68.8 \%)$ & 0.15 \\
\hline iNO & $8(3.4 \%)$ & $5(2.7 \%)$ & $3(18.8 \%)$ & $<0.001$ \\
\hline Sildenafil & $8(3.4 \%)$ & $5(2.7 \%)$ & 3 (18.8\%) & $<0.001$ \\
\hline
\end{tabular}

Data shown as $\mathrm{n}(\%)$ or median [interquartile range]. $\mathrm{P}$ values represent results of Kruskal-Wallis analysis of rank sum for tests. SGA, small for gestational age; IVF-ET, in vitro fertilization and embryo transfer; PROM, prolonged rupture of membranes; MV, mechanical ventilation; PDA, patent ductus arteriosus; IVH, intraventricular hemorrhage; NEC, necrotizing enterocolitis; ROP, retinopathy of prematurity; BPD, bronchopulmonary dysplasia; $\mathrm{PH}$, pulmonary hypertension; CMV, cytomegalovirus; EUGR, extrauterine growth restriction; iNO, inhaled nitric oxide.

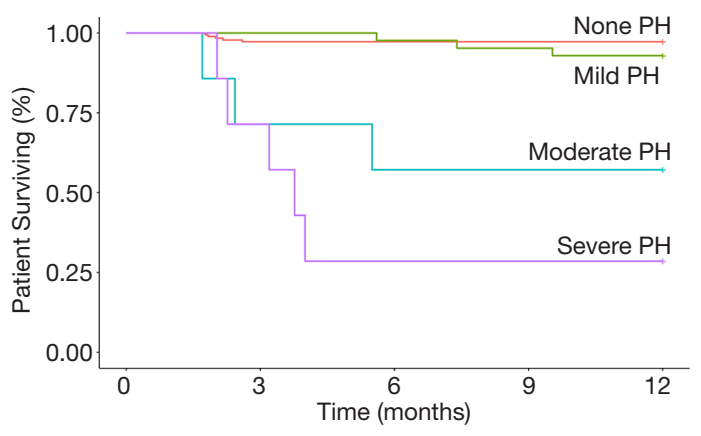

Figure 2 Kaplan-Meier survival curves according to $\mathrm{PH}$ severity. Kaplan-Meier graphs demonstrating the probability of survival during the first year after birth of infants with mild, moderate or severe $\mathrm{PH}$. $\mathrm{PH}$, pulmonary hypertension.

covariates could improve it to 0.69 .

\section{Discussion}

This study compared outcomes in a retrospective cohort of infants with BPD by the echocardiogram-assessed PH severity. We found that $\mathrm{PH}$ severity was associated with adverse outcomes including mortality and readmission during the first year after birth.

Many previous studies have paid close attention to the risk factors for $\mathrm{BPD}$-associated $\mathrm{PH}$ in preterm infants (7,12,22,27-30). While most of these studies focused on clinical characteristics and early recognition of BPDassociated $\mathrm{PH}$ in preterm infants during the initial NICU hospitalization. In addition, only a few studies mentioned the prognosis of $\mathrm{PH}$ in infants with BPD $(11,14,31)$. Mourani et al. (15) found early pulmonary vascular disease (PVD) was a risk factor for BPD and late PVD, and then described the association between early PVD and late respiratory outcomes at 2 year of corrected age. Choi et al. (14) described the relationship between $\mathrm{BPD}$-associated $\mathrm{PH}$ and worsen neurodevelopmental outcomes of preterm infants at 18-24 months of corrected age. Lagatta et al. (11) found that BPD-associated PH was associated with hospital readmissions and death. None of these prognostic studies evaluated the association between the severity of BPDassociated $\mathrm{PH}$ and adverse outcomes after initial NICU discharge. In this study, association between $\mathrm{PH}$ severity and adverse outcomes including mortality and readmission through the first year of life were examined.

Echocardiography conducted in previous studies was limited for assessing severity of $\mathrm{PH}$ compared with cardiac catheterization $(15,16,32)$. Nawaytou et al. (16) found that echocardiography performed well in premature infants screened for BPD. Conversely, compared with the degree of pulmonary vascular resistance assessed by cardiac catheterization, the grade of increased PAP was poor. Although there was no cardiac catheterization classification in this study, we found that the PH severity assessed by echocardiography was significantly associated with prognosis and the predictive value of mortality and readmission. This suggests that echocardiography remains a valuable diagnostic test for assessing the severity of BPD associated $\mathrm{PH}$.

We identified significant associations between moderate/ severe $\mathrm{BPD}$-associated $\mathrm{PH}$ and mortality from 36 weeks PMA to 1-year age, though mild PH was not significantly associated with mortality. Male sex, preeclampsia and iNO were also associated with mortality. Preeclampsia is a risk factor for death in the first year of life, which inform maternal disease may contribute late diseases of infants, though the mechanism is still unclear (33). More non-survivors received iNO treatment compared with 


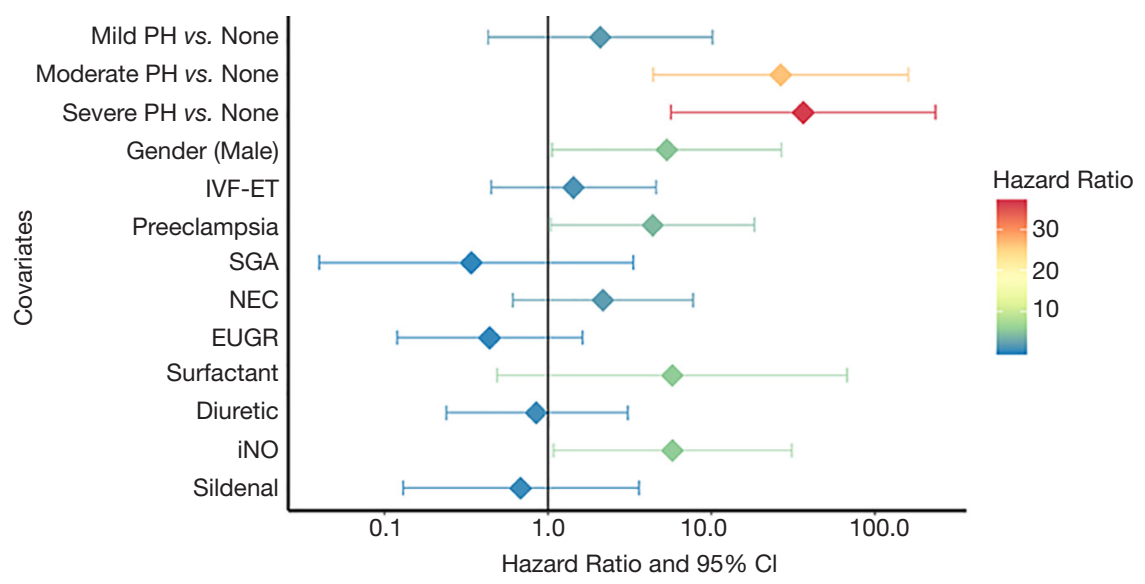

Figure 3 Parameter estimates from multivariable cox regression. Adjusted hazard ratios from cox regression modeling mortality during the first one year of life based on PH severity, gender, IVF-ET, preeclampsia, SGA, NEC, EUGR, surfactant administration, diuretic administration, iNO and sildenafil administration. Moderate and severe $\mathrm{PH}$ had the largest estimated association with mortality during the first one year of life (moderate PH vs. none HR =26.58, 95\% CI: 4.40-160.78, P<0.001; severe PH vs. none HR =36.49, 95\% CI: 5.65-235.84, $\mathrm{P}<0.001)$. Male, preeclampsia and iNO were also significantly associated with survival outcomes $(\mathrm{HR}=5.34,95 \% \mathrm{CI}$ : 1.06-26.90, $\mathrm{P}=0.04$; $\mathrm{HR}=4.38$, 95\% CI: 1.04-18.43, P=0.04 and HR =5.78, 95\% CI: 1.08-31.08, P=0.04, respectively). PH, pulmonary hypertension; IVF-ET, in vitro fertilization and embryo transfer; SGA, small for gestational age; NEC, necrotizing enterocolitis; EUGR, extrauterine growth restriction; iNO, inhaled nitric oxide.

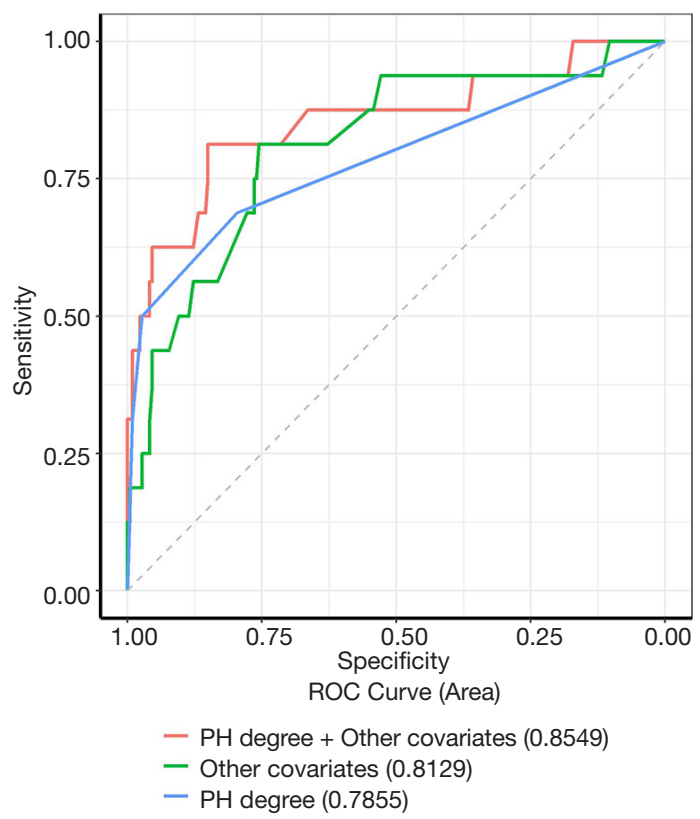

Figure 4 Receiver operating characteristic curves demonstrating that $\mathrm{PH}$ severity is a strong predictor of death in the first year of life. Cox regression models: $\mathrm{PH}$ severity model, model including selected covariates listed in the Figure 3 and model using the other selected covariates except PH severity. AUC of the PH severity model was 0.79 and could reach 0.85 when incorporating other covariates. $\mathrm{PH}$, pulmonary hypertension; AUC, area under curve. survivors. For most patients with $\mathrm{PH}$, fluid management and supplemental oxygen therapy used to avoid episodic or sustained hypoxemia was the main treatment. Only critical patients might have chance to receive $\mathrm{PH}$-targeted therapy, including iNO and sildenafil, which was unapproved by National Medical Products Administration and difficult to get in NICUs of China.

Although in our univariate analysis and previous studies, the number of days in MV and BPD status was also strongly associated with mortality. Yet, because of their potential collinearity with $\mathrm{PH}$ severity, they were removed from the multivariate regression model.

Furthermore, the moderate/severe $\mathrm{PH}$ are strong predictors of death in the first year of life. $\mathrm{PH}$ severity together with other perinatal and postnatal factors provide practical prognostic information for caregivers to identify high-risk infants, who might need invasive tests or interventions to reduce mortality. Cardiac catheterization is critical for infants with moderate/severe BPD-associated $\mathrm{PH}$ to be able to confirm echocardiographic diagnosis and assess potential cardiac structural changes, such as shunt lesions and pulmonary venous stenosis (34). There are few specific drugs for BPD-associated PH (35-39), thus identifying high-risk infants less invasively would allow for better clinical trials design to reduce mortality. 
We found only mild $\mathrm{PH}$ was associated with readmission in the first year after birth. In this cohort, only four patients with moderate $\mathrm{PH}$ and two with severe $\mathrm{PH}$ survived to 1 year of age. Nonetheless, the simple size was too small to identify the association between moderate/severe $\mathrm{PH}$ and readmission. Continued clinical care for BPD and monitoring is recommended for infants with mild $\mathrm{PH}$ and echocardiogram following-up program is essential. Krishnan et al. (17) recommended to repeat echocardiogram every 2-4 months as long as $\mathrm{O}_{2}$ required. There is controversy regarding how useful $\mathrm{PH}$-targeted medications benefit the infants with only mild $\mathrm{PH}$, thus more prospective studies are needed to develop effective interventions and strategies (17).

This study has several potential limitations. It's a singlecenter retrospective observational cohort study, and $9.9 \%$ infants with BPD didn't perform echocardiogram or loss of following-up, which indicates potential selection bias. However, a previous study which enrolled the similar subjects suggested minimal impact of this bias on the final findings in the sensitivity analysis (11). PH severity was assessed by reviewing echocardiographic records. In addition, follow-up data collected through questionnaires may also be at high risk of system bias. Still, all the echocardiography was performed according to the same standard by the same one cardiologist and checked by the same one senior cardiologist at CHFU. Regular training of record abstracts minimizes system deviation. The sample size is relatively small, especially to infants with moderate/ severe $\mathrm{PH}$, yet the small sample size doesn't limit the ability to identify statistically significant differences in outcomes. The study didn't collect data on socioeconomic status of participants' families. There may be complex associations between the socioeconomic status of the participants' families and their prognosis for differential access to health services (11). Previous studies suggested the utility and accuracy of echocardiography are limited to diagnose $\mathrm{PH}$ for infants with post-tricuspid valve shunt and recommended quantitative index, such as tissue Doppler imaging (TDI), tricuspid annular plane systolic excursion (TAPSE) and pulmonary artery acceleration time (PAAT) as predictors for $\mathrm{PH}(7,16,40)$. However, detailed data on shunt lesions and PAAT measurements were not available in our study for further investigation. This may improve the accuracy of echocardiography.

\section{Conclusions}

In conclusion, this study demonstrates that echocardiogram- assessed $\mathrm{PH}$ severity is associated with prognostic outcomes including mortality and readmission in very preterm infants with BPD. Furthermore, the severity of $\mathrm{PH}$ based on echocardiography examination is a potential predictor of mortality in the first year of life. Echocardiography is a useful and less invasive tool to assess the severity of $\mathrm{PH}$ regardless of possibly limited accuracy. Future research should focus on the potential predictive value of specific echocardiographic measurements. The severity of $\mathrm{PH}$ was prospectively assessed. In addition, the development of a prognostic scoring system based on echocardiography may be considered.

\section{Acknowledgments}

We are grateful to Prof. Wei-Li Yan, from Department of Clinical Epidemiology, Children's Hospital of Fudan University, for her assistance of statistical analyses.

Funding: None.

\section{Footnote}

Reporting Checklist: The authors have completed the STROBE reporting checklist. Available at http://dx.doi. org/10.21037/tp-20-192

Data Sharing Statement: Available at http://dx.doi. org/10.21037/tp-20-192

Conflicts of Interest: All authors have completed the ICMJE uniform disclosure form (available at http://dx.doi. org/10.21037/tp-20-192). The authors have no conflicts of interest to declare.

Ethical Statement: The authors are accountable for all aspects of the work in ensuring that questions related to the accuracy or integrity of any part of the work are appropriately investigated and resolved. The study was conducted in accordance with the Declaration of Helsinki (as revised in 2013). This study was approved by the Children's Hospital of Fudan University Institutional Review Board (IRB No. 2018-301), with a waiver of informed consent for retrospectively use of routine clinical data.

Open Access Statement: This is an Open Access article distributed in accordance with the Creative Commons Attribution-NonCommercial-NoDerivs 4.0 International License (CC BY-NC-ND 4.0), which permits the non- 
commercial replication and distribution of the article with the strict proviso that no changes or edits are made and the original work is properly cited (including links to both the formal publication through the relevant DOI and the license). See: https://creativecommons.org/licenses/by-nc-nd/4.0/.

\section{References}

1. Northway WH, Rosan RC, Porter DY. Pulmonary disease following respiratory therapy of hyaline-membrane disease. Bronchopulmonary dysplasia. N Engl J Med 1967;276:357-68.

2. Jobe AH, Abman SH. Bronchopulmonary Dysplasia: A Continuum of Lung Disease from the Fetus to the Adult. Am J Respir Crit Care Med 2019;200:659-60.

3. Jiang S, Yan W, Li S, et al. Mortality and Morbidity in Infants <34 Weeks' Gestation in 25 NICUs in China: A Prospective Cohort Study. Front Pediatr 2020;8:33.

4. Lapcharoensap W, Lee HC, Nyberg A, et al. Health Care and Societal Costs of Bronchopulmonary Dysplasia. Neoreviews 2018;19:e211-e223.

5. Duijts L, van Meel ER, Moschino L et al. European Respiratory Society guideline on long term management of children with bronchopulmonary dysplasia. Eur Respir J 2020;55:1900788.

6. Wu KY, Jensen EA, White AM, et al. Characterization of Disease Phenotype in Very Preterm Infants with Severe Bronchopulmonary Dysplasia. Am J Respir Crit Care Med 2020;201:1398-406.

7. Khemani E, McElhinney DB, Rhein L, et al. Pulmonary artery hypertension in formerly premature infants with bronchopulmonary dysplasia: clinical features and outcomes in the surfactant era. Pediatrics 2007;120:1260-9.

8. Altit G, Dancea A, Renaud C, et al. Pathophysiology, screening and diagnosis of pulmonary hypertension in infants with bronchopulmonary dysplasia - A review of the literature. Paediatr Respir Rev 2017;23:16-26.

9. Bhat R, Salas AA, Foster C, et al. Prospective analysis of pulmonary hypertension in extremely low birth weight infants. Pediatrics 2012;129:e682-9.

10. Check J, Gotteiner N, Liu X, et al. Fetal growth restriction and pulmonary hypertension in premature infants with bronchopulmonary dysplasia. J Perinatol 2013;33:553-7.

11. Lagatta JM, Hysinger EB, Zaniletti I, et al. The Impact of Pulmonary Hypertension in Preterm Infants with Severe Bronchopulmonary Dysplasia through 1 Year. J Pediatr 2018;203:218-24.e3.

12. Nagiub M, Kanaan U, Simon D, et al. Risk Factors for
Development of Pulmonary Hypertension in Infants with Bronchopulmonary Dysplasia: Systematic Review and Meta-Analysis. Paediatr Respir Rev 2017;23:27-32.

13. Mirza H, Ziegler J, Ford S, et al. Pulmonary Hypertension in Preterm Infants: Prevalence and Association with Bronchopulmonary Dysplasia. J Pediatr 2014;165:909-14.e1.

14. Choi EK, Shin SH, Kim E, et al. Developmental outcomes of preterm infants with bronchopulmonary dysplasiaassociated pulmonary hypertension at 18-24 months of corrected age. BMC Pediatr 2019;19:26.

15. Mourani PM, Sontag MK, Younoszai A, et al. Clinical utility of echocardiography for the diagnosis and management of pulmonary vascular disease in young children with chronic lung disease. Pediatrics 2008;121:317-25.

16. Nawaytou H, Steurer MA, Zhao Y, et al. Clinical Utility of Echocardiography in Former Preterm Infants with Bronchopulmonary Dysplasia. J Am Soc Echocardiogr 2020;33:378-88.e1.

17. Krishnan U, Feinstein JA, Adatia I, et al. Evaluation and Management of Pulmonary Hypertension in Children with Bronchopulmonary Dysplasia. J Pediatr 2017;188:24-34.e1.

18. Abman SH, Hansmann G, Archer SL, et al. Pediatric Pulmonary Hypertension. Circulation 2015;132:2037-99.

19. Jobe AH, Bancalari E. Bronchopulmonary dysplasia. Am J Respir Crit Care Med 2001;163:1723-9.

20. Zhu L, Zhang R, Zhang S, et al. Chinese neonatal birth weight curve for different gestational age. Zhonghua Er Ke Za Zhi 2015;53:97-103.

21. Clark RH, Thomas P, Peabody J. Extrauterine growth restriction remains a serious problem in prematurely born neonates. Pediatrics 2003;111:986-90.

22. Mourani PM, Sontag MK, Younoszai A, et al. Early Pulmonary Vascular Disease in Preterm Infants at Risk for Bronchopulmonary Dysplasia. Am J Respir Crit Care Med 2015;191:87-95.

23. Levy PT, Patel MD, Choudhry S, et al. Evidence of Echocardiographic Markers of Pulmonary Vascular Disease in Asymptomatic Infants Born Preterm at One Year of Age. J Pediatr 2018;197:48-56.e2.

24. Musewe NN, Smallhorn JF, Benson LN, et al. Validation of Doppler-derived pulmonary arterial pressure in patients with ductus arteriosus under different hemodynamic states. Circulation 1987;76:1081-91.

25. Ge Z, Zhang Y, Kang W, et al. Noninvasive evaluation of interventricular pressure gradient across ventricular septal defect: a simultaneous study of Doppler echocardiography 
and cardiac catheterization. Am Heart J 1992;124:176-82.

26. Experts consensus on the management of neonatal pulmonary hypertension. Zhonghua Er Ke Za Zhi 2017;55:163-8.

27. Vayalthrikkovil S, Vorhies E, Stritzke A, et al. Prospective study of pulmonary hypertension in preterm infants with bronchopulmonary dysplasia. Pediatr Pulmonol 2019;54:171-8.

28. Trittmann JK, Gastier-Foster JM, Zmuda EJ, et al. A single nucleotide polymorphism in the dimethylarginine dimethylaminohydrolase gene is associated with lower risk of pulmonary hypertension in bronchopulmonary dysplasia. Acta Paediatr 2016;105:e170-5.

29. Mestan KK, Gotteiner N, Porta N, et al. Cord Blood Biomarkers of Placental Maternal Vascular Underperfusion Predict Bronchopulmonary Dysplasia-Associated Pulmonary Hypertension. J Pediatr 2017;185:33-41.

30. Trittmann JK, Nelin LD, Zmuda EJ, et al. Arginase I gene single-nucleotide polymorphism is associated with decreased risk of pulmonary hypertension in bronchopulmonary dysplasia. Acta Paediatr 2014;103:e439-43.

31. Mourani PM, Mandell EW, Meier M, et al. Early Pulmonary Vascular Disease in Preterm Infants Is Associated with Late Respiratory Outcomes in Childhood. Am J Respir Crit Care Med 2019;199:1020-7.

32. Carlton EF, Sontag MK, Younoszai A, et al. Reliability of Echocardiographic Indicators of Pulmonary Vascular Disease in Preterm Infants at Risk for Bronchopulmonary

Cite this article as: Du Y, Yuan L, Zhou JG, Huang XY, Lin SB, Yuan M, He Y, Mao WY, Ai DY, Chen C. Echocardiography evaluation of bronchopulmonary dysplasiaassociated pulmonary hypertension: a retrospective observational cohort study. Transl Pediatr 2021;10(1):73-82. doi: 10.21037/tp20-192
Dysplasia. J Pediatr 2017;186:29-33.

33. Morrow LA, Wagner BD, Ingram DA, et al. Antenatal Determinants of Bronchopulmonary Dysplasia and Late Respiratory Disease in Preterm Infants. Am J Respir Crit Care Med 2017;196:364-74.

34. Laux D, Rocchisani M, Boudjemline Y, et al. Pulmonary Hypertension in the Preterm Infant with Chronic Lung Disease can be Caused by Pulmonary Vein Stenosis: A Must-Know Entity. Pediatr Cardiol 2016;37:313-21.

35. Hwang SK, O YC, Kim NS, et al. Use of Inhaled Iloprost in an Infant with Bronchopulmonary Dysplasia and Pulmonary Artery Hypertension. Korean Circ J 2009;39:343-5.

36. Wardle AJ, Wardle R, Luyt K, et al. The utility of sildenafil in pulmonary hypertension: a focus on bronchopulmonary dysplasia. Arch Dis Child 2013;98:613-7.

37. Kumar P. Use of inhaled nitric oxide in preterm infants. Pediatrics 2014;133:164-70.

38. Ferdman DJ, Rosenzweig EB, Zuckerman WA, et al. Subcutaneous treprostinil for pulmonary hypertension in chronic lung disease of infancy. Pediatrics 2014;134:e274-8.

39. Tan K, Krishnamurthy MB, O Heney JL, et al. Sildenafil therapy in bronchopulmonary dysplasia-associated pulmonary hypertension: a retrospective study of efficacy and safety. Eur J Pediatr 2015;174:1109-15.

40. Levy PT, Patel MD, Groh G, et al. Pulmonary Artery Acceleration Time Provides a Reliable Estimate of Invasive Pulmonary Hemodynamics in Children. J Am Soc Echocardiogr 2016;29:1056-65. 


\section{Supplementary}

\section{Appendix 1 Definitions of comorbidities.}

SGA: Birth weight was below the 10th percentile for corresponding sex and gestational age.

PDA: Patent ductus arteriosus was diagnosed on an echo at any point during admission.

IVH: Grade 3 or 4 intraventricular hemorrhage.

NEC: Including all stages of necrotizing enterocolitis.

ROP: Including all stages of retinopathy of prematurity.

CMV infection: PCR for CMV-DNA was positive in blood or urine sample.

Sepsis: Including culture-positive bacteremia sepsis and clinical sepsis.

EUGR: Growth values were below the 10th percentile for expectation based on estimated postmenstrual age at hospital discharge.

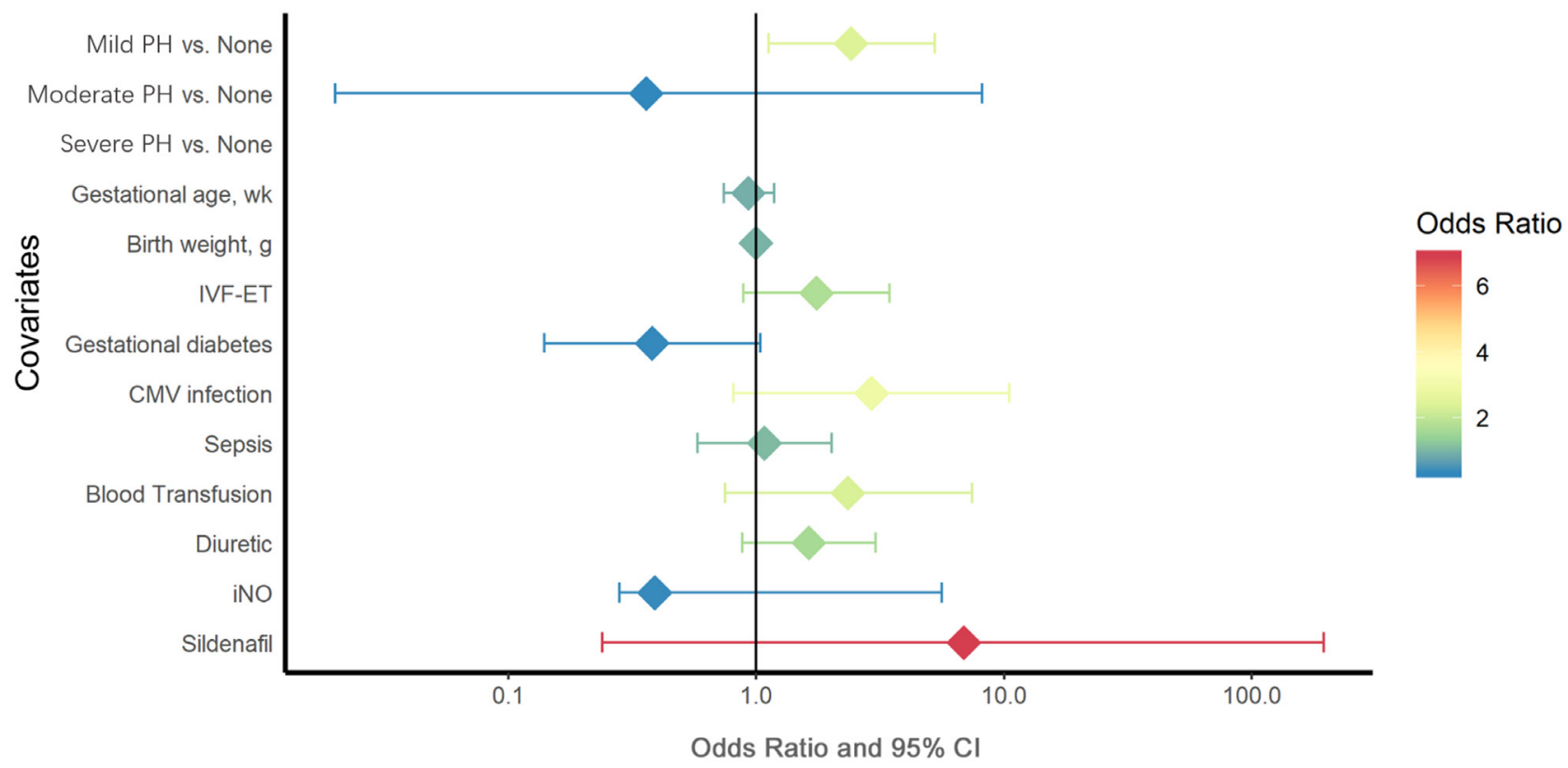

Figure S1 Parameter estimates from multivariable logistic regression. Adjusted odds ratios from logistic regression modeling readmission during the first one year of life based on PH severity, gestational age, birth weight, IVF-ET, gestational diabetes, CMV infections, sepsis, blood transfusion, diuretic, iNO and sildenafil administration. Mild $\mathrm{PH}$ was significantly associated with readmission $(\mathrm{OR}=2.42,95 \% \mathrm{CI}$ : 1.12-5.26, P=0.025). PH, pulmonary hypertension; IVF-ET, in vitro fertilization and embryo transfer; CMV, cytomegalovirus; iNO, inhaled nitric oxide. 
Table S1 Grading criterions for pulmonary hypertension associated with bronchopulmonary dysplasia based on echocardiogram findings

\begin{tabular}{ll}
\hline Grade & Echocardiogram findings \\
\hline None & SPAP $\leq 35 \mathrm{mmHg}$, no RVH, normal RV size and function \\
Mild & SPAP $>35 \mathrm{mmHg}$ and $\leq 50 \mathrm{mmHg}$, mild right ventricular hypertrophy or dilatation, right ventricular function may be normal \\
Moderate & SPAP $>50 \mathrm{mmHg}$ and $\leq 70 \mathrm{mmHg}$, moderate right ventricular hypertrophy or dilatation \\
Severe & SPAP $>70 \mathrm{mmHg}$, shunt with predominant right-to-left gradient, Severe right ventricular hypertrophy, right ventricular \\
& dysfunction, right ventricular dilatation
\end{tabular}

sPAP, systolic pulmonary artery pressure.

Table S2 Echocardiographic characteristics in patients with pulmonary hypertension

\begin{tabular}{lccc}
\hline Variable & Mild PH & Moderate PH & Severe PH \\
\hline SPAP, mmHg & $44[41-47]$ & $62[50-65]$ & $05]$ \\
RV hypertrophy & $4(9.6 \%)$ & 0 & 0 \\
Mild & 0 & 0 & 0 \\
Moderate & 0 & 0 & 0 \\
Severe & $10(23.8 \%)$ & 0 & 0 \\
RV dilation & 0 & $4(57.1 \%)$ & $2(28.6 \%)$ \\
Mild & 0 & 0 & $2(28.6 \%)$ \\
Moderate & 0 & 0 & $4(57.1 \%)$ \\
Severe & 0 & 0 & 0 \\
RV dysfunction & 0 & 0 \\
Right-to-left shut & 0 & 0 \\
\hline
\end{tabular}

Data shown as $\mathrm{n}(\%)$ or median [interquartile range]. SPAP, systolic pulmonary artery pressure; RV, right ventricle.

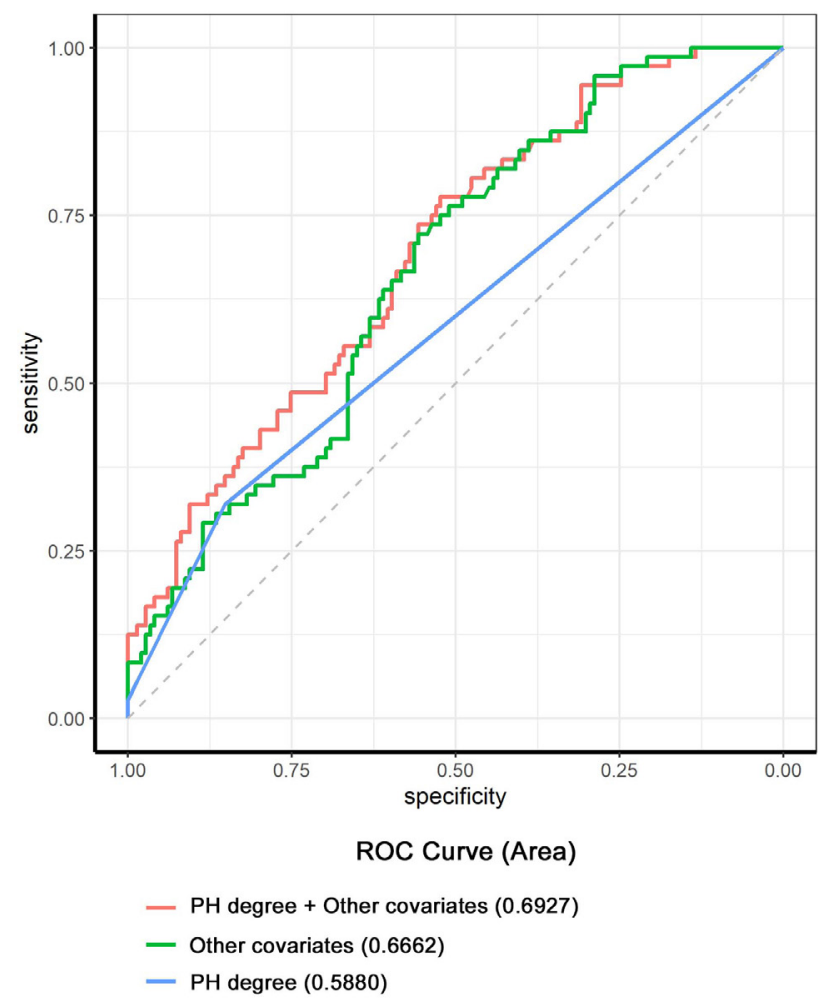

Figure S2 Receiver operating characteristic curves suggest that PH severity together other covariates can inform readmission in the first year of life. Logistic regression models: PH severity model, model including selected covariates listed in the Figure S1 and model using the other selected covariates except PH severity. AUC of the PH severity model was 0.58 , and addition of other covariates could improve it to 0.69. PH, pulmonary hypertension. 
Table S3 Subject characteristics by readmission status

\begin{tabular}{|c|c|c|c|c|}
\hline Variable & All subjects & No readmission & Readmission & $P$ value \\
\hline Number of subjects with outcome & 221 & 149 & 72 & \\
\hline Gestational age, wk & 28 [27-29] & 28 [27-29] & 27 [26-29] & 0.07 \\
\hline Birth weight, $g$ & $1,080[930-1,250]$ & $1,080[950-1,275]$ & $1,050[880-1,188]$ & 0.13 \\
\hline SGA & $18(8.1 \%)$ & $11(7.4 \%)$ & $7(9.7 \%)$ & 0.55 \\
\hline Gender (male) & $136(61.4 \%)$ & $90(60.4 \%)$ & $46(63.9 \%)$ & 0.62 \\
\hline \multicolumn{5}{|l|}{ Maternal complications } \\
\hline Multiple gestation & $80(36.2 \%)$ & $53(35.6 \%)$ & $27(37.5 \%)$ & 0.78 \\
\hline IVF-ET & $61(27.6 \%)$ & $35(23.5 \%)$ & $26(36.1 \%)$ & 0.05 \\
\hline Preeclampsia & $31(14.0 \%)$ & $20(13.4 \%)$ & $11(15.3 \%)$ & 0.71 \\
\hline Gestational diabetes & $33(14.9 \%)$ & $27(18.1 \%)$ & $6(8.3 \%)$ & 0.06 \\
\hline PROM & $68(30.8 \%)$ & $42(28.2 \%)$ & $26(36.1 \%)$ & 0.23 \\
\hline Intrauterine distress & $24(10.9 \%)$ & $17(11.4 \%)$ & $7(9.7 \%)$ & 0.71 \\
\hline Antenatal corticosteroids & $105(47.5 \%)$ & $71(47.7 \%)$ & $34(47.2 \%)$ & 0.95 \\
\hline Cesarean section & $90(40.9 \%)$ & $60(40.5 \%)$ & $30(41.7 \%)$ & 0.87 \\
\hline \multicolumn{5}{|l|}{ Postnatal hospitalization } \\
\hline Surfactant & $175(79.2 \%)$ & $121(81.2 \%)$ & $54(75.0 \%)$ & 0.29 \\
\hline Mechanical ventilation support at 7 days & $144(65.2 \%)$ & $101(67.8 \%)$ & $43(59.7 \%)$ & 0.24 \\
\hline Days on MV & $8[3-19]$ & $7[3-13]$ & 13 [7-32] & $<0.001$ \\
\hline PDA & $186(88.6 \%)$ & $125(88.7 \%)$ & $61(88.4 \%)$ & 0.96 \\
\hline IVH (Grade 3 or 4) & $22(10.0 \%)$ & $14(9.4 \%)$ & $8(11.1 \%)$ & 0.69 \\
\hline NEC & $34(15.4 \%)$ & $25(16.8 \%)$ & $9(12.5 \%)$ & 0.41 \\
\hline ROP & $143(64.7 \%)$ & $93(62.4 \%)$ & $50(69.4 \%)$ & 0.31 \\
\hline BPD (NHLBI multi-level) & & & & 0.008 \\
\hline Mild & $86(38.9 \%)$ & $66(44.3 \%)$ & $20(27.8 \%)$ & \\
\hline Moderate & $55(24.9 \%)$ & $37(24.8 \%)$ & $18(25.0 \%)$ & \\
\hline Severe & $80(36.2 \%)$ & $46(30.9 \%)$ & $34(47.2 \%)$ & \\
\hline PH severity & & & & 0.002 \\
\hline None & 176 (79.6\%) & 127 (85.2\%) & $49(68.1 \%)$ & \\
\hline Mild & $39(17.7 \%)$ & $20(13.4 \%)$ & $19(26.4 \%)$ & \\
\hline Moderate & $4(1.8 \%)$ & $2(1.3 \%)$ & $2(2.8 \%)$ & \\
\hline Severe & $2(0.9 \%)$ & $0(0 \%)$ & $2(2.8 \%)$ & \\
\hline CMV infection & $14(6.3 \%)$ & $5(3.5 \%)$ & $9(12.5 \%)$ & 0.009 \\
\hline Sepsis & $112(50.7 \%)$ & $71(47.7 \%)$ & $41(56.9 \%)$ & 0.20 \\
\hline EUGR & 163 (73.8\%) & 108 (72.8\%) & 55 (76.4\%) & 0.54 \\
\hline Blood transfusion & $190(86.0 \%)$ & $123(82.6 \%)$ & $67(93.1 \%)$ & 0.04 \\
\hline Postnatal steroids & $120(54.3 \%)$ & 77 (51.7\%) & $43(59.7 \%)$ & 0.26 \\
\hline Diuretic & $111(50.2 \%)$ & $69(46.3 \%)$ & $42(58.3 \%)$ & 0.10 \\
\hline iNO & $5(2.7 \%)$ & $3(2.0 \%)$ & $2(2.8 \%)$ & 0.72 \\
\hline Sildenafil & $5(2.7 \%)$ & $1(0.7 \%)$ & $4(5.6 \%)$ & 0.02 \\
\hline
\end{tabular}

Data shown as $\mathrm{n}(\%)$ or median [interquartile range]. $\mathrm{P}$ values represent results of Kruskal-Wallis analysis of rank sum for tests. SGA, small for gestational age; IVF-ET, in vitro fertilization and embryo transfer; PROM, prolonged rupture of membranes; MV, mechanical ventilation; PDA, patent ductus arteriosus; IVH, intraventricular hemorrhage; NEC, necrotizing enterocolitis; ROP, retinopathy of prematurity; BPD, bronchopulmonary dysplasia; PH, pulmonary hypertension; CMV, cytomegalovirus; EUGR, extrauterine growth restriction; iNO, inhaled nitric oxide. 
Table S4 Parameter estimates from multivariable cox regression

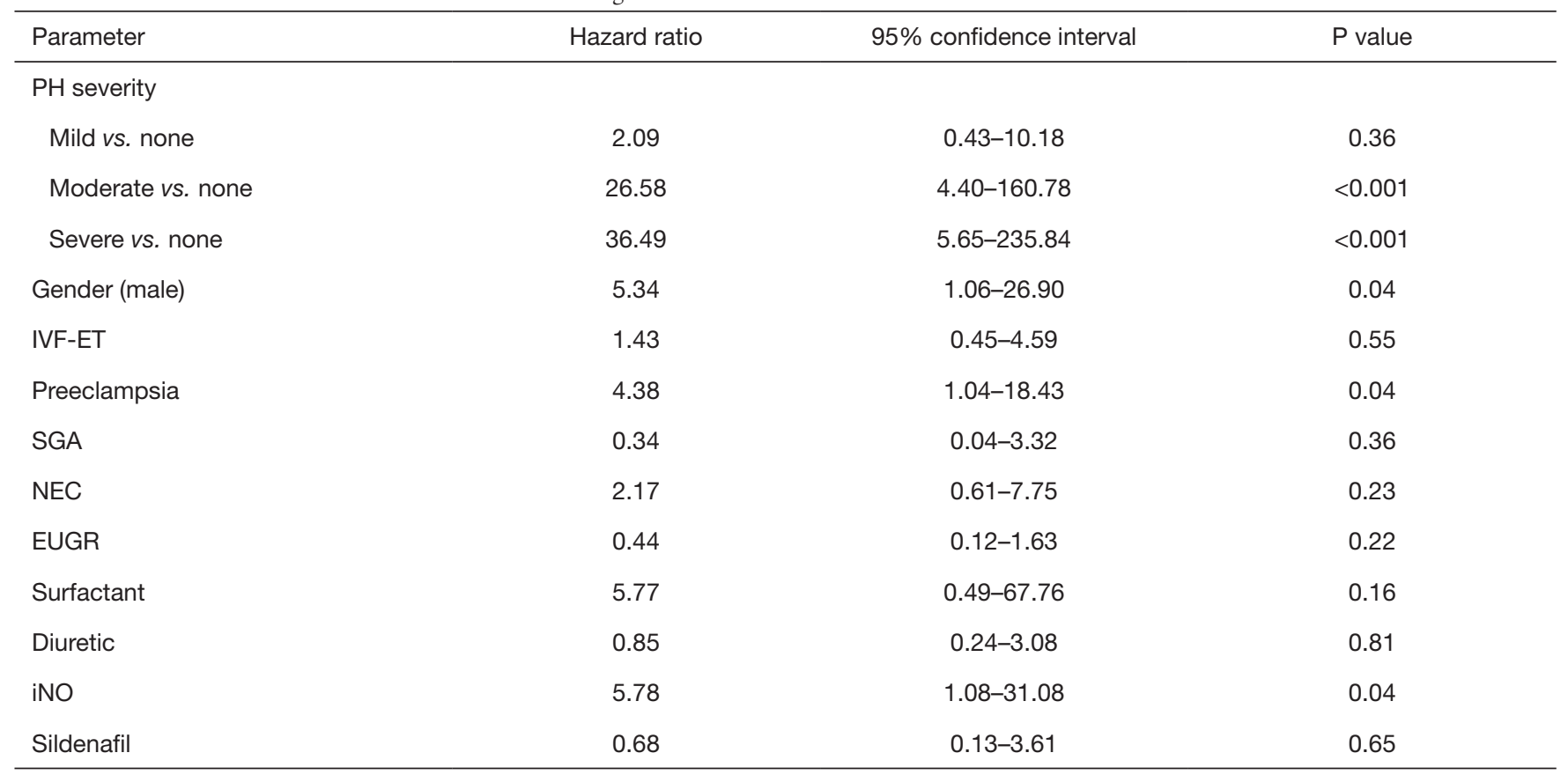

$\mathrm{PH}$, pulmonary hypertension; IVF-ET, in vitro fertilization and embryo transfer; SGA, small for gestational age; NEC, necrotizing enterocolitis; EUGR, extrauterine growth restriction; iNO, inhaled nitric oxide.

Table S5 Parameter estimates from multivariable logistic regression

\begin{tabular}{|c|c|c|c|}
\hline Parameter & Odds ratio & $95 \%$ confidence interval & $P$ value \\
\hline Mild vs. none & 2.42 & $1.12-5.26$ & 0.03 \\
\hline Moderate vs. none & 0.36 & $0.02-8.14$ & 0.52 \\
\hline Severe vs. none & Omitted & & \\
\hline Birth weight, $g$ & 1.00 & $0.99-1.00$ & 0.49 \\
\hline IVF-ET & 1.75 & $0.89-3.45$ & 0.11 \\
\hline Gestational diabetes & 0.38 & $0.14-1.04$ & 0.06 \\
\hline CMV infection & 2.92 & $0.81-10.50$ & 0.10 \\
\hline Diuretic & 1.63 & $0.88-3.03$ & 0.12 \\
\hline iNO & 0.39 & $0.28-5.61$ & 0.49 \\
\hline Sildenafil & 6.88 & $0.24-194.36$ & 0.26 \\
\hline
\end{tabular}

$\mathrm{PH}$, pulmonary hypertension; IVF-ET, in vitro fertilization and embryo transfer; CMV, cytomegalovirus; iNO, inhaled nitric oxide. 